\title{
A IMPORTÂNCIA DOS GÊNEROS TEXTUAIS NO PROCESSO DE ENSINO-APRENDIZAGEM DE LÍNGUA PORTUGUESA
}

\section{ARTIGO ORIGINAL}

ROCHA, Anna Gabrielle Amorim ${ }^{1}$

ROCHA, Anna Gabrielle Amorim. A importância dos gêneros textuais no processo de ensino-aprendizagem de Língua Portuguesa. Revista Científica Multidisciplinar Núcleo do Conhecimento. Ano 05, Ed. 03, Vol. 10, pp. 18-32. Março de 2020. ISSN: 2448-0959, Link de acesso: https://www.nucleodoconhecimento.com.br/letras/importancia-dos-generos

\section{RESUMO}

As novas concepções de linguagem apresentadas por muitos pesquisadores na área da linguagem e as atuais orientações metodológicas dos Parâmetros Curriculares Nacionais de Língua Portuguesa inserem em suas discussões a necessidade de implementação de novas estratégias de ensino. Com base nestas novas perspectivas teórico-metodológicas, este trabalho intitulado "A importância dos gêneros textuais no processo de ensino-aprendizagem da língua portuguesa", inserido na área de concentração da Linguística Textual, pretende mostrar a importância, em termos pedagógicos, dos gêneros textuais enquanto objeto de ensino privilegiado na prática cotidiana do ensino e aprendizagem de Língua Portuguesa. Para estes fins, apresenta os conceitos de gêneros sob a ótica de alguns autores da área como Bakhtin (1992), Marcuschi (2004 e 2005), Dolz e Schneuwly (2004), como parte do processo de construção do referencial teórico aqui adotado. Metodologicamente, configura-se como uma pesquisa de natureza bibliográfica, numa construção dialética e abordagem qualitativa, a partir da pesquisa exploratória. Considerando a abordagem realizada, verificou-se o quanto os gêneros textuais são relevantes no processo de ensino-

${ }^{1}$ Licenciada em Letras Língua Portuguesa e Literatura - UEA/2019 Bacharela em Comunicação Social/Jornalismo - UFAM/2013. 
aprendizagem de língua materna, ao se apresentarem como elementos responsáveis pela interação e constituição do sujeito em sociedade e possibilitar ao aluno o aperfeiçoamento de sua competência leitora, de produção textual e de oralidade, já que o estudo do gênero, de forma ampla, permite várias abordagens no que diz respeito à concepção da linguagem.

Palavras-chave: Gêneros Textuais, Língua Portuguesa, ensino-aprendizagem.

\section{INTRODUÇÃO}

As discussões em torno das dificuldades de efetivação do processo de ensinoaprendizagem de língua materna, neste caso específico, a Língua Portuguesa, tem gerado, principalmente entre os educadores, a necessidade de se buscar alternativas e/ou estratégias que os ajudem a otimizar ou minimizar tais problemáticas. Diante dessas preocupações, torna-se cada vez mais pertinente a necessidade de se repensar as práticas pedagógicas, que por muito tempo tem orientado o trabalho dos educadores em sala de aula, a fim de que se encontrem perspectivas e sejam definidos novos rumos no que diz respeito ao estudo da linguagem.

Dentre as inúmeras perspectivas que visam sistematizar os procedimentos de ensino de língua materna, a inserção dos gêneros textuais como objeto de ensino, tem se mostrado um importante aliado neste processo, uma vez que se acredita que estes colaboram no desenvolvimento da linguagem e ainda, que tais atividades pretendem ampliar tanto a competência leitora, a capacidade de produção textual, quanto o conhecimento gramatical da língua.

Com base nas novas concepções de linguagem, apresentadas por muitos pesquisadores na área da linguagem e as atuais orientações metodológicas dos Parâmetros Curriculares Nacionais de Língua Portuguesa, reconhecendo as dificuldades e necessidade de implementação de novas estratégias de ensino, é que este trabalho intitulado "A importância dos gêneros textuais no processo de ensinoaprendizagem da Língua Portuguesa" tem como principal finalidade mostrar a 
importância, em termos pedagógicos, dos gêneros textuais como estratégia privilegiada na prática cotidiana do ensino e aprendizagem da Língua Portuguesa.

O interesse por esta temática deu-se após as observações feitas durante os estágios supervisionados I (Ensino Fundamental) e II (Ensino Médio), onde se notou que os gêneros textuais, enquanto instrumento pedagógico, ainda não são explorados de forma adequada e ainda não conseguem atender os anseios de um ensino pautado no desenvolvimento das competências comunicativas dos alunos, seja no âmbito da leitura, da fala ou da escrita. Diante disso, surgiu o seguinte questionamento: Qual a importância de trabalhar o texto explorando os diferentes gêneros textuais?

É baseado neste questionamento que o presente trabalho tem como principal objetivo fazer uma abordagem mais detalhada como forma de ressaltar a necessidade de mostrar a importância dos gêneros textuais para o ensino e aprendizagem de Língua Portuguesa. Para tanto, fez-se necessário explanar os diferentes conceitos de gêneros textuais sob a ótica dos autores que tratam sobre 0 assunto, tais como Bakhtin (1992), Antunes (2002), Marcuschi (2004, 2005 e 2008), Dolz e Schneuwly (2004), entre outros, a fim de se ter uma visão aprofundada e detalhada de tais conceitos na medida em que são analisados, dada a sua importância para o estudo.

Pretendeu-se ainda, como objetivos específicos, explicar de que forma a utilização dos mais variados textos/gêneros textuais auxiliam no aprimoramento da capacidade de leitura e produção textual dos alunos. E em meio a estas discussões, procurou-se também discutir sobre a condição e papel do professor, entendido como o responsável por fazer determinadas escolhas e adotar as estratégias necessárias para o bom desempenho de seus alunos em sala de aula.

A partir desse contexto e pressupostos, colocando em papel de destaque os gêneros textuais, é que o presente trabalho se desenvolve, e em vista dos seus objetivos, leva em consideração as contribuições teóricas que fundamentam as concepções de linguagem e o processo de ensino e aprendizagem da língua materna. Assim como, as orientações que norteiam o uso dos gêneros textuais pelos professores que em consequência, reflete no desempenho educacional de seus alunos. 
Nesse sentido, esse trabalho é de delineamento bibliográfico, haja vista que não foi necessária a pesquisa de campo, pois buscou-se fazer uma reflexão sobre o estudo e ensino por meio dos gêneros textuais baseando-se apenas em fundamentos teóricos de autores renomados que lidam com essa temática. Além disso, caracterizase como uma pesquisa qualitativa, visto que o principal objetivo é interpretar o fenômeno em observação, nesse caso, os gêneros textuais e também exploratória por haver uma investigação aprofundada sobre o assunto e que servirá como referência para mais pesquisas que virão direcionadas ao ensino da Língua Portuguesa.

Em função dessa abordagem metodológica, o trabalho organiza-se em 5 partes fundamentais. Na primeira, apresenta-se um breve histórico e panorama dos gêneros textuais, com o intuito de destacar as especificidades das teorias e das pesquisas acerca desse conceito e sua relação com o ensino de Língua Portuguesa, evidenciando, logo após, a relevância do texto dentro deste processo educativo, assim como a influência dos gêneros textuais nas habilidades de leitura, oralidade e produção textual dos alunos. O último ponto a ser discutido, como parte do aporte teórico, diz respeito à escolha ou seleção dos textos/gêneros para o ensino de Língua Portuguesa, dando ênfase para o papel do professor neste processo tão significativo. Segue-se, logo após, os procedimentos metodológicos adotados na execução da pesquisa. E, por fim, são apresentadas as considerações finais, onde se faz uma discussão geral sobre a importância dos gêneros textuais no processo de ensino e aprendizagem de Língua Portuguesa.

\section{GÊNEROS TEXTUAIS: UMA BREVE APRESENTAÇÃO}

A alusão ao termo gênero textual, por convenção, dada a sua recorrência na vida cotidiana e principalmente nas aulas de Língua Portuguesa, remete-nos às diferentes formas, características e linguagens dos diversos textos, sejam eles orais ou escritos, tradicionais ou digitais, que fazem parte das relações comunicativas e do convívio social humano. Em vista desta primeira percepção, toma-se, a exemplo, categorias como: contos, lendas, fábulas, poemas, cardápios, charges, tirinhas, histórias em quadrinhos, notícias, reportagens, resenhas, e-mails, enfim, uma lista infindável, que vai dos mais simples aos mais complexos, no que diz respeito a seu uso e praticidade. 
No entanto, para além desta primeira impressão, o estudo sobre gênero textual e sua relação com a prática comunicativa e interpessoal humana, vem adquirindo ao longo dos anos uma dimensão mais ampla. Isto se dá em decorrência dos vários estudos que se apresentam na área da linguagem que visam estabelecer a relação entre teoria e prática, ou seja, faz-se necessário, antes de tudo, se compreender as concepções de linguagem a partir de uma perspectiva histórica, cultural e social, para assim inserir, de forma prática, os gêneros textuais enquanto mecanismos de socialização até se chegar a sua importância enquanto ferramenta de ensino-aprendizagem.

Deste modo, o termo gênero, que era antes usado apenas como referência para os textos literários, atualmente assume uma dimensão mais abrangente. Bakhtin (1992, p. 279), que relaciona "todas as esferas da atividade humana [...] à utilização da língua" e pondera que cada uma dessas esferas "comporta um repertório de gêneros do discurso", traz em meio a essas discussões e assertivas, uma série de estudos referente às teorias da linguagem e necessidades de compreensão em torno dos gêneros textuais. Dentre as afirmações que ganham recorrente notoriedade nos trabalhos voltados a esta temática, encontra-se a defendida por Marcuschi (2002, p.22) onde, segundo o autor, "a comunicação verbal só é possível por algum gênero textual". O que dá a questão do gênero, em conformidade com os dois autores, uma abrangência inesgotável.

Nesse sentido, os gêneros textuais, de acordo com a visão dos autores mencionados, são todos os textos (orais e escritos) que circulam socialmente e tem por função efetivar o processo de comunicação e interação verbal entre os indivíduos. O que insere também no âmbito da discussão, a função social do gênero, já que este viabiliza a interação e o convívio em sociedade. Os gêneros passam a ter, a partir dessa visão, um caráter extremamente pragmático e contextualizado. Com isso, se está diante de um conceito que não se refere apenas a um dos aspectos didático-metodológicos do ensino de Língua Portuguesa em sala de aula, e sim a um conceito intimamente relacionado à constituição do sujeito em sociedade, a partir de uma atividade interativa, efetivada prioritariamente pela linguagem. 
Indo ao encontro desta perspectiva pragmática Marcuschi (2008, p.149) apresenta sua definição de gêneros textuais, que, em suma, mostra-os como "formas de ação social". Mas, como ele mesmo pondera, a definição formal dos gêneros é algo muito difícil. É quando ele propõe que, a depender do sentido em que se observa, os gêneros textuais podem ser: "uma categoria cultural, um esquema cognitivo, uma forma de ação social, uma estrutura textual, uma forma de organização social e/ou uma ação retórica". Para ele, os gêneros são "fenômenos históricos, profundamente vinculados à vida cultural e social" e se constituem como "formas de ação incontroláveis" que têm a função de "ordenar e estabilizar as atividades do dia- a- dia". Tais ponderações reforçam a abrangência teórica e prática conferida aos gêneros textuais, visto a sua necessidade de delimitação e compreensão.

Chega-se, deste modo, a proposição que os gêneros são a forma natural pela qual usamos a língua para nos comunicar, ou seja, não é possível falar nenhuma palavra sem utilizar um gênero textual, assim, não há comunicação sem eles. Por isso, o trabalho com a noção de gênero permite uma abordagem nos mais diferentes aspectos da língua que, enquanto fenômenos históricos e culturais, se adequam e determinam as variadas situações comunicativas produzidos em sociedade. Em decorrência do caráter dinâmico e social conferida ao gênero, Antunes (2002, p. 69) afirma que

Os gêneros são histórico-culturais, isto é, sedimentam-se em momentos e em espaços da vida das comunidades; isto é, cada lugar e cada época são marcados pela predominância de certos gêneros, os quais, nesta contingência, podem aflorar permanecer, modificar-se, transmutar-se, desaparecer; na verdade, os grupos sociais é que regulam as condições do percurso que os gêneros realizam.

O que estabelece a estreita relação existente entre concepção de gênero e constituição do sujeito, visto que, dentro desta dinâmica histórico-cultural que os gêneros se inscrevem, acabam por determinar as relações socioculturais e dão a linguagem um papel preponderante no processo de interação humana. Reforçando esta íntima relação, Marcuschi (2008) afirma que, como seres sociais, desde nossa constituição, estamos envolvidos numa "máquina sociodiscursiva", sendo os gêneros 
textuais um dos instrumentos mais poderosos, por ser de sua competência boa parte de nossa inserção social.

Deste modo, em meio a vasta abrangência, faz-se necessário delimitar o estudo sobre o gênero, a fim de se encontrar direcionamentos específicos a serem trabalhados e estabelecer as possíveis finalidades, ao apresentá-lo enquanto mecanismo de interação, e ainda situá-lo no universo didático-pedagógico como importante ferramenta de ensino-aprendizagem e suas concretas contribuições.

\subsection{O ENSINO DA LÍNGUA PORTUGUESA NA PERSPECTIVA DO GÊNERO}

Visto seu potencial de interação verbal e sua estreita relação com os aspectos históricos e sociais que constituem o sujeito, os gêneros textuais se apresentam com os requisitos necessários à prática didático-pedagógico referente ao ensino da língua materna. Parte-se da premissa defendida por Marcuschi onde "é impossível se comunicar verbalmente a não ser por um gênero, assim como é impossível se comunicar verbalmente a não ser por um texto". (MARCUSCHI, 2007, p.22). Deste modo, se o texto/gênero textual funciona como meio de interação, este processo tende a ser facilitado quando se tem em vista trabalhar o ensino da língua portuguesa na perspectiva do gênero textual.

Em seus estudos Dolz e Schneuwly (2004), dão destaque à questão do gênero textual, principalmente as relacionadas ao ensino da Língua Portuguesa ao acreditarem que a abordagem e estudo da língua devem ser feitos por meio dos textos e sugerem a utilização dos diferentes gêneros textuais, sejam eles orais ou escritos em sala de aula.

As ideias desses autores sobre a utilização dos gêneros textuais no ensino da Língua Portuguesa convergem inteiramente com a proposta dos Parâmetros Curriculares Nacionais (PCNs) de Língua Portuguesa (1998) ao apresentarem os gêneros textuais como ferramentas de ensino na prática de leitura e produção de texto e como aliados no processo de ensino-aprendizagem da língua materna. Nesse sentido, propõe-se a 
adoção de uma metodologia que venha desvencilhar o ensino de língua materna da prática tradicional, ancorada no aspecto meramente normativo e conceitual. No entanto, como afirma Romeu (2010), essa metodologia que adota preferencialmente os gêneros textuais nas práticas em sala de aula, não impede, nem deve impedir o trabalho com os elementos gramaticais da língua. Ao contrário, o texto funciona também como um lugar propício à compreensão de tais elementos, a depender de metodologias que saibam aproveitar o potencial linguístico do texto em uso.

Desse modo, conforme a autora, o trabalho com o gênero deve ser o de, além de apresentar variadas estratégias de leitura e também de produção textual, auxiliar nos estudos do vocabulário e principalmente da gramática, tratando-se aqui, não precisamente de uma substituição, mas sim de uma reformulação que obtenha resultados satisfatórios.

Tem-se agora a necessidade de fazer que as aulas de Língua Portuguesa, tendo como enfoque 0 uso de textos/gêneros textuais, se preocupe com o uso efetivo da linguagem a partir de uma abordagem sociointeracionista, ou seja, a linguagem enquanto forma ou processo de interação do sujeito nos mais diferentes contextos do qual fazem parte. Com base nisso os PCNs, a partir desta proposta, enfatizam que "não há linguagem no vazio, seu grande objetivo é a interação, a comunicação com o outro, dentro de um espaço social" (BRASIL, 1998, p.5). O que acaba por integrar efetivamente $\mathrm{O}$ uso do texto com os processos de interação social dentro de um contexto amplo que abarca a linguagem e suas produções de sentido.

Em vista de tal proposta, faz-se necessário agora, inserir de forma prática, metodologias de ensino que possam garantir que os gêneros textuais se apresentem como aliados concretos no processo de ensino-aprendizagem de língua materna. Segundo Geraldi (2006) e Possenti (2006), contemporaneamente, o ensino da língua apresenta-se como uma prática considerada insuficiente à tentativa de fazer das aulas de Língua Portuguesa meios significativos de apreensão de conhecimento. Faz-se, portanto, necessário buscar alternativas capazes de suprir tal dificuldade. 
Essa mudança enfatizada pelos linguistas seria também a transformação desejada pelos PCNs, ao propor uma metodologia, neste caso, a partir da utilização dos gêneros textuais. Para que isso aconteça, requer-se o entendimento da funcionalidade do texto, entendido até aqui como elemento primordial neste processo que visa garantir as aulas de língua materna, maior capacidade de integração e eficiência.

\subsubsection{A QUESTÃO DA TEXTUALIDADE: O TEXTO COMO OBJETO DE ENSINO}

Dentro da perspectiva histórica, com base nos estudos da Linguística Textual, o texto é apresentado, de acordo com Segate (2010, p.01) como o objeto de estudo desta recente ciência da linguagem, e como tal apresenta unidades linguísticas e propriedades específicas. A autora também afirma que ao longo do tempo o conceito de texto precisou ser reformulado. Isto porque "investigar a palavra ou a frase isolada não permite entender os diversos fenômenos linguísticos, pois esses só podem ser explicados dentro do próprio texto".

Em meio às discussões em torno de uma nova concepção metodológica que visa melhor desempenho no ensino da Língua Portuguesa, verifica-se, de forma unânime, a relevância de apresentar o texto como elemento primordial no processo de ensinoaprendizagem adquirido pelo aluno em sala de aula. É isto que defende a proposta apresentada pelos PCNs quando encara o texto enquanto unidade de sentido e comunicação. Claro que isto se aplica de forma prática quando se leva em conta fatores como o nível de conhecimento de cada aluno e seu contexto social, de modo a ajustar à série e a sua vida pessoal.

Diante dessas atenções dadas ao texto, faz-se necessário entender, tanto em termos teóricos quanto práticos, em que exatamente consiste este importante objeto de estudo. De acordo com Koch (2003, p. 31), o texto é entendido como uma

[...] manifestação verbal, constituída de elementos linguísticos de diversas ordens, selecionados e dispostos de acordo com as virtualidades que cada língua põe à disposição dos falantes no curso de uma atividade verbal, de modo a facultar aos 
interactantes não apenas a produção de sentidos, como a de fundear a própria interação como prática sociocultural.

Entende-se, neste sentido, que o texto, enquanto materialidade linguística exerce por excelência sua função comunicativa e enquanto manifestação verbal facilita o processo de interação entre os sujeitos. Este se organiza de modo a estabelecer e gerar sentidos, ou seja, se adequado a determinadas situações de comunicação de forma coerente. Leva-se em consideração, como destaca Antunes (2002) que o que determina ou dá relevância ao texto não são simplesmente seus elementos imanentes e sim fatores contextuais que condicionam, determinam e lhe conferem destaque. Daí a necessidade de eleger como objeto de estudo o texto, na sua dupla face de produção e recepção, recobrando ao estudo da língua maior importância. Isto por considerar que "o conhecimento dos textos e de suas formas de ocorrência constitui, afinal, parte do saber das pessoas acerca da língua e de seu funcionamento" (Op. Cit. p. 68).

Quanto às condições de produção de sentidos Wittke (2012, p. 21) enfatiza que "todo texto é determinado de acordo com a interação comunicativa estabelecida entre o produtor e o receptor, o que pressupõe regras, valores e normas de conduta, advindas dos papéis sociais que os sujeitos desempenham na sociedade".

Nesse aspecto, o entendimento sobre o texto e sua relação com o processo de ensino e aprendizagem requer bastante atenção, pois é nele que se deposita, a depender de sua escolha, a expectativa de uma abordagem metodológica eficiente e de um instrumento que garanta a interação do seu potencial leitor com o outro e com o mundo que o cerca, priorizando suas competências, sejam elas manifestadas pela fala ou pela escrita.

\subsubsection{GÊNEROS TEXTUAIS E AS HABILIDADES DE LEITURA, PRODUÇÃO TEXTUAL E ORALIDADE}

Dentre as principais preocupações da prática pedagógica de Língua Portuguesa, em função dos resultados que se deseja alcançar, está a capacidade de explorar as 
habilidades de leitura, produção textual e a oralidade dos alunos. Suscitar estas competências, torna-se, por via de regra, uma "obrigação" por parte do professor de Língua Portuguesa através de suas estratégias didático-metodológicas. Isto porque, se tais dificuldades não são sanadas mediante as atividades realizadas nesta disciplina, consequentemente estes alunos terão "problemas" com as demais, que também exigem, apesar de não ser na mesma proporção, habilidades nessa ordem.

Esse planejamento didático pauta-se nas orientações dos Parâmetros Curriculares tendo como base a organização de situações de aprendizagem a partir de gêneros adequados para o trabalho com linguagem oral e a linguagem escrita e que sejam apropriados aos diferentes níveis de escolaridade (BRASIL, 1998). Em vista dessas orientações, faz-se indispensável o uso coerente de práticas que venham satisfazer tal anseio. Os gêneros textuais, mais especificamente, os variados textos que se apresentam enquanto objeto de estudo nas aulas de Língua Portuguesa, passam a configurar, dentro da perspectiva interacionista, a ferramenta mais eficaz para as práticas de leitura, produção textual e oralidade.

A atividade de leitura, de acordo Antunes (2003, p. 67), deve ser uma "atividade de interação entre sujeitos". Advêm desse processo de interação as relações estabelecidas entre autor-texto-leitor, nos quais os leitores acionam seus conhecimentos prévios para atribuir sentido ao que foi lido, podendo assim compreender as intenções, atento às marcas e pistas deixadas pelo autor. Esta perspectiva dá à questão da leitura não apenas a possibilidade de se decodificar de maneira mecânica os sinais gráficos, e sim de garantir, enquanto competência leitora, uma visão global do texto. É preciso pois, que se privilegie, no ato de ler, a capacidade de compreensão e interpretação, na qual os alunos venham integrar as suas habilidades linguísticas e comunicativas em sua completude, como muito se postula nos estudos dos gêneros textuais.

A habilidade escrita, de acordo com Lima (2017), desempenha o papel de marca concreta ou local da produção de sentidos gerados pela leitura. É nas atividades de produção textual que se têm uma percepção se as atividades de leitura desempenharam efeitos concretos e/ou positivos. Faz-se necessário, dessa forma, 
observar nestas práticas os elementos estruturais e as marcas linguísticas referentes e adequados ao gênero e a situação comunicativa em que o leitor/autor está inserido. Podendo esses elementos e marcas serem também evidenciados nas práticas de oralidade. Permitindo ao aluno o desenvolvimento da competência linguística mais usual. O que, de certo modo, o prepara para as mais diversas circunstâncias de interação verbal.

Como postula Lima (2017, p.3) "essa prática pedagógica centrada no tripé leitura, produção e análise de textos exige uma diversificação de situações didáticas pensadas para o desenvolvimento da linguagem oral formal e ampliação das competências leitoras e escritas". Isto, evidentemente, considerando o tipo de gênero a ser escolhido, em função do nível de escolaridade dos alunos e os objetivos que se pretendem alcançar.

Neste intuito, faz-se necessário apresentar, dentro das atividades pedagógicas de Língua Portuguesa, possíveis propostas que visem estudar a língua com base nas unidades básicas que constituem tal ensino, sejam elas através de práticas de leitura, de oralidade ou produção textual.

\section{A ESCOLHA DOS GÊNEROS PARA O ENSINO DE LÍNGUA PORTUGUESA E O PAPEL DOCENTE}

Em torno de toda essa discussão, que dá aos gêneros textuais relevância no processo de ensino e aprendizagem de Língua Portuguesa e reconhecendo sua abrangência inesgotável, tem-se, pois, a preocupação do quanto ou quem pode se responsabilizar pela escolha de tais textos, a fim de se encontrar equilíbrio e fazer das práticas didáticas com estes instrumentos, meios significativos de educação.

De acordo com Marcuschi (2008) não se pode definir que há gêneros ideais para o ensino. Pode-se, no entanto, identificar exemplares genéricos que permitem uma progressão no grau de dificuldade, partindo do mais simples para o mais complexo. Ele também frisa sua preocupação em que sejam escolhidos gêneros voltados para a 
compreensão de textos e também para a produção, de forma cautelosa, visto que há habilidades diferenciadas.

As variedades de gêneros textuais também são consideradas nos PCNs, e a escolha dos exemplares a serem ensinados, de acordo com Dias (2012, p. 08), está intimamente relacionada com as habilidades de fala e escuta, leitura e escrita. Para isso, os PCNs sugerem quadros de agrupamentos de gêneros que podem ser utilizados para orientação no processo de ensino. Segue, portanto, o quadro:

Quadro 1: Agrupamentos sugeridos pelo PCNs para a prática de produção de textos orais e escritos

\begin{tabular}{|c|c|c|c|}
\hline \multicolumn{2}{|c|}{ Linguagem oral } & \multicolumn{2}{|c|}{ Linguagem escrita } \\
\hline Literários & $\begin{array}{ll}\S \text { Canção } & \\
\S & \text { Textos } \\
\text { dramáticos } & \end{array}$ & Literários & $\begin{array}{l}\text { § Crônica } \\
\S \text { Conto } \\
\S \text { Poema }\end{array}$ \\
\hline Imprensa & $\begin{array}{l}\S \text { Notícia } \\
\S \text { Entrevista } \\
\S \text { Debate } \\
\S \text { Depoimento }\end{array}$ & Imprensa & $\begin{array}{l}\S \text { Notícia } \\
\S \text { Artigo } \\
\S \text { Carta do Leitor } \\
\S \text { Entrevista }\end{array}$ \\
\hline $\begin{array}{l}\text { Divulgação } \\
\text { Científica }\end{array}$ & $\begin{array}{l}\S \text { Seminário } \\
\S \text { Debate }\end{array}$ & $\begin{array}{l}\text { Divulgação } \\
\text { Científica }\end{array}$ & $\begin{array}{l}\S \text { Relatório de } \\
\text { experiências } \\
\S \text { Esquema e } \\
\text { resumo de artigos } \\
\text { ou verbetes } \\
\S \text { Enciclopédia }\end{array}$ \\
\hline
\end{tabular}

Fonte: BRASIL, 1998, p. 54. 
Esses agrupamentos de gêneros são separados de acordo com a função desejada, ou seja, são escolhidos, separadamente, gêneros para linguagem oral e escrita. Para cada um dos dois tipos de linguagem, selecionam-se gêneros das esferas literária, de imprensa, de divulgação científica e de publicidade.

Cabe, pois, ao professor fazer essas escolhas, atento a estas novas perspectivas. Esta torna-se uma responsabilidade que exige um esforço, pois apesar de ser um aspecto positivo para suas aulas, a ação docente ainda precisa superar críticas relacionadas a sua atuação. Nesse ínterim, Geraldi (2006) critica a maneira como se encontra o ensino de língua materna e defende a necessidade de mudança na prática pedagógica do professor de LP.

Parece-me que o mais caótico da atual situação do ensino de Língua Portuguesa em escolas de primeiro grau consiste precisamente no ensino, para alunos que nem sequer dominam a variedade culta, de uma metalinguagem de análise dessa variedade - com exercícios contínuos de descrição gramatical, estudo de regras e hipóteses de análise de problemas que mesmo especialistas não estão seguros de como resolver (p.45).

Esses questionamentos sobre o papel docente tornam-se recorrentes e são baseados nas discussões que visam encontrar mecanismos que o auxilie neste processo, cabendo também a este profissional estar aberto a estas novas perspectivas. Reiterando estas críticas, em torno do papel do professor, Wittke (2012, p.14) destaca que,

A ação docente não vem sendo planejada e realizada por meio de atividades significativas e de permanente interação verbal, as quais possam colocar o aluno em situações reais de comunicação (falando e escrevendo), o que acaba tornando a aula de língua um exercício mecânico, muitas vezes, destituído de sentido.

Sob esse prisma, o professor tem que exercer o papel de mediador, que além de propor metodologias diferenciadas de leitura e produção textual, promova atividades com o intuito de explorar o estudo do texto e seus variados gêneros sob a ótica de 
seu funcionamento e estrutura, considerando os sentidos que ele produz, para tornar seu aluno competente em reconhecê-los e utilizá-los nos mais diferentes lugares sociais de comunicação.

Nessa perspectiva de alcançar o resultado desejado, no entendimento de Furlanetto (2007), a aprendizagem implica processos complexos de mediação, orientação, de trabalho cooperativo, envolvendo a interação humana numa dinâmica complexa.

Diante do exposto, o estudo pautado em gêneros textuais não só auxilia o processo de ensino e aprendizagem da língua materna, mas proporciona e incentiva o hábito da leitura, da produção textual e da oralidade. Cabendo assim ao professor, a escolha dos gêneros conforme aos níveis de assimilação dos conteúdos por parte dos seus alunos.

\section{PROCEDIMENTOS METODOLÓGICOS}

Nesse tópico, procura-se explicitar os processos metodológicos que nortearam o caminhar da pesquisa até a sua conclusão.

A pesquisa se inclina para o método de abordagem qualitativa, que de acordo com Marconi e Lakatos (2011) trata de uma pesquisa que tem como premissa, entender e interpretar fenômenos sociais inseridos em um dado contexto. Para tanto, constitui-se numa pesquisa de delineamento bibliográfico, que de acordo com Gil (2002, p. 44),

a pesquisa bibliográfica é desenvolvida com base em material já elaborado, constituído principalmente de livros e artigos científicos. Embora em quase todos os estudos seja exigido algum tipo de trabalho dessa natureza, há pesquisas desenvolvidas exclusivamente a partir de fontes bibliográficas.

Essa fase fora iniciada pelo levantamento de materiais já publicados, como livros, artigos, teses, tendo como objetivo a familiarização ao assunto pesquisado, no caso, sobre os Gêneros Textuais e a sua importância no ensino e aprendizagem da LP. 
Por se tratar de uma pesquisa com uma temática pouco discutida na cidade onde se desenvolveu o trabalho o presente estudo também se caracteriza como uma pesquisa exploratória, que de acordo com Gil (2002, p. 41), têm como principal objetivo proporcionar a familiarização com o problema pesquisado, com propósito de torná-lo mais claro. Ainda segundo esse autor, este tipo de pesquisa tem como principal objetivo o aperfeiçoamento de ideias ou a descoberta de intuições. Nesta perspectiva, fizeram-se necessários seguir as seguintes etapas:

1ㄹ Etapa - Busca de Fontes: Essa etapa constituiu na identificação das fontes capazes de fornecer as respostas necessárias para à solução do problema da pesquisa. Ao todo foram selecionados: 05 artigos científicos, a saber: Gêneros textuais no ensino de língua portuguesa; Gêneros textuais: referência para o ensino de língua portuguesa; Gêneros textuais no ensino de língua portuguesa: experiências no estágio supervisionado; Gêneros textuais para a produção de textos escritos no livro didático e Gêneros orais e escritos na escola, 04 livros: Gêneros orais e escritos na escola; Produção textual, análise de gêneros e compreensão; Sobre o ensino de português na escola e Concepções de linguagem e ensino de português, além de leituras em sítios da internet e revistas eletrônicas.. Sendo essas todas referenciadas no final deste trabalho.

2a Etapa - Coleta de dados: Essa etapa consistiu na leitura no material bibliográfico organizado, onde se requereu imensa atenção e foco para que fosse possível a identificação de informações e de dados para a pesquisa.

Gil (2002, p. 77), postula que se pode classificar os tipos de leituras do material de acordo com o avanço da pesquisa. Segundo ele, a primeira leitura é a "Leitura Exploratória" que tem como objetivo verificar se a obra consultada interessa ou não a pesquisa. A segunda é a "Leitura Seletiva", que determina se o material de fato interessa à pesquisa é mais profunda que a exploratória. Logo após, tem-se a "Leitura analítica" que é feita em base nos textos selecionados e que tem com finalidade ordenar e sumariar as informações. E a última é a "Leitura interpretativa", essa etapa do processo de leitura e é a mais complexa. É neste processo que se deve conferir o 
significado aos resultados obtidos com a leitura. É necessário ligar os dados com o conhecimento obtido.

Após essa etapa de leitura dos materiais partiu-se para a 3를 Etapa, que correspondeu ao fichamento dos materiais selecionados. Esta etapa teve como objetivo, identificar nas obras consultadas, os conteúdos que interessavam a pesquisa, assim como tecer comentários acerca das obras e a ordenação dos registros.

Feito isso, seguiu-se a $4^{\mathrm{a}}$ e última etapa que foi voltada a redação do texto. Nessa etapa fora exposto o relato da compreensão dos conteúdos pesquisados, atentandose a organização e transcrição das análises obtidas nas fases anteriores como objetivo de mostrar a importância, em termos pedagógicos, dos gêneros textuais enquanto objeto de ensino privilegiado na prática cotidiana do ensino e aprendizagem de Língua Portuguesa.

\section{CONSIDERAÇÕES FINAIS}

Sob a ótica de renomados autores que trabalham a questão da linguagem e o processo de ensino-aprendizagem que visam dar ao ensino novas perspectivas em um contexto educacional que ainda requer atenção, a inserção dos gêneros textuais apresenta-se como essencial, uma vez que colabora para o desenvolvimento da linguagem e funciona como instrumento de trabalho para professores de Língua Portuguesa. Dar relevância a esta importante ferramenta de ensino, apoiados nas propostas dos próprios PCNs, transforma os textos/gêneros textuais em elos de interação e formação do próprio sujeito em sociedade.

Como perspectiva didático-pedagógica, verificou-se através deste estudo que a proposta de utilização dos gêneros tende a contribuir para o aperfeiçoamento da formação e atuação docente, visto que, cria oportunidades de se relacionar teoria e prática ao transformar os saberes teórico-metodológicos apreendidos em efetivas práticas pedagógicas. Tais práticas, como visto, podem influenciar de forma significativa, em pensar nas vantagens para o aluno, no aprimoramento da capacidade 
de leitura, produção textual e oralidade através dos mais diversos gêneros textuais, pois garantem uma abordagem dinâmica e acionam aspectos históricos e ideológicos.

Torna-se, portanto, cada vez mais importante a reflexão sobre o tema, na tentativa de encontrar, além de soluções e ações que promovam um ensino significativo, também meios que auxiliem tanto o professor em formação quanto os que já atuam, a fim de redirecioná-los a práticas eficientes para seu trabalho.

Esse estudo pode ser recomendado como uma ferramenta complementar de pesquisa aos interessados na temática, principalmente a aqueles que se debruçam na incansável necessidade de encontrar alternativas para o melhor funcionamento do ensino, em particular, aos professores de Língua Portuguesa, que apesar dos desafios diários, encontram em sua missão de ensinar, a motivação necessária para persistir.

\section{REFERÊNCIAS}

BAKHTIN, Mikhail. Estética da criação verbal. Tradução: Maria Ermantina Galvão G. Pereira. 3.ed. São Paulo: Martins Fontes, 2000.

BRASIL, Secretaria de Educação Fundamental. Parâmetros curriculares nacionais: terceiro e quarto ciclos do ensino fundamental: Língua Portuguesa. Brasília: MEC/SEF, 1998.

CORRÊA, Hydelvídia Cavalcante de Oliveira; SOUZA, Lygia de Lima: Pesquisa e Produção Acadêmica em Letras I. - Manaus: UEA edições, 2018.

DIAS, Laice Raquel. Gêneros textuais para a produção de textos escritos no livro didático. Disponível em: http://www.ileel.ufu.br/anaisdosielp/wpcontent/uploads/2014/07/volume_2_artigo_166.pdf. Acesso em: 08 de Abril de 2019.

DOLZ, Joaquim; SCHNEUWLY, Bernand. Gêneros orais e escritos na escola. Campinas, SP: Mercado de Letras, 2004. 278 p. (Tradução e organização: Roxane Rojo; Glaís Sales Cordeiro). 
FURLANETTO, Maria Marta. Práticas discursivas: desafio no ensino de Língua Portuguesa. In: CORREA, DjaneAntonucci. e SALEH, Pascoalina Bailon de Oliveira. Práticas de letramento no ensino; leitura, escrita e discurso. São Paulo: Parábola, 2007.

GERALDI, João Wanderley (org). 0 texto na sala de aula. 4. ed. São Paulo: Àtica, 2006 .

GERALDI, João Wanderley. Concepções de linguagem e ensino de português. In:

Gil, Antônio Carlos. Como elaborar projetos de pesquisa. 4. ed. São Paulo: Atlas, 2002.

KOCH, I. V. O texto e a construção dos sentidos. São Paulo: Contexto, 2003.

LIMA, Fernanda Barboza de. Gêneros textuais no ensino de língua portuguesa: experiências no estágio supervisionado. Disponível em: https://www.editorarealize.com.br/revistas/sinalge/trabalhos/TRABALHO_EV066_MD 1_SA2_ID1562_23032017225333.pdf. Acesso em: 04 de Abril de 2019.

MARCONI, Marina de Andrade; LAKATOS, Eva Maria. Metodologia Cientifica. São Paulo. Atlas, 2011.

MARCUSCHI, Luiz Antônio. Produção textual, análise de gêneros e compreensão. São Paulo: Parábola Editorial, 2008.

MARCUSCHI, Luiz Antônio. Produção textual. Gêneros textuais: definição e funcionalidade. In: DIONÍSIO, A. P.; MACHADO, A. R.; BEZERRA, M. A. (Org.). Gêneros textuais e ensino. 4. ed. Rio de Janeiro: Lucerna, 2005.

ORLANDI, Eni P. Análise de discurso: princípios e procedimentos. 8. ed. Campinas, SP: Pontes, 2009.

POSSENTI, Sírio. Gramática e política. In: GERALDI, João Wanderley (org). O texto na sala de aula. 4.ed. São Paulo: Àtica, 2006. 
POSSENTI, Sírio. Sobre o ensino de português na escola. In: GERALDI, João Wanderley (org). O texto na sala de aula. 4.ed. São Paulo: Àtica, 2006.

ROMEU, Silvanya Suellem de Lima. Gêneros textuais: referência para o ensino de língua portuguesa. Disponível em: http://www.editorarealize.com.br/revistas/conedu/trabalhos/TRABALHO_EV056_MD 1_SA15_ID8012_17082016160903.pdf. Acesso em: 04 de Abril de 2019.

Severino, Antônio Joaquim, 1941- Metodologia do trabalho científico - Antônio Joaquim Severino. - 21. ed. rev. e ampl. — São Paulo: Gortez, 2000.

SEGATE, Aline. Gêneros textuais no ensino de língua portuguesa. Disponível em: http://www.revistas.usp.br/linhadagua/article/view/37333. Acesso em: 23 de Abril de 2019.

WITTKE, Cleide Inês. O importante papel do texto nas aulas de língua materna. Disponível em: http://www.ileel.ufu.br/anaisdosielp/wpcontent/uploads/2014/06/volume_2_artigo_074.pdf. Acesso em: 24 de Abril de 2019.

Enviado: Janeiro, 2020.

Aprovado: Março, 2020. 